\title{
Vibration Characteristics of Fully Enclosed Sound Barriers on Railway Bridges under the Movement of Trains
}

\author{
Hao Li, ${ }^{1}$ Xiao-Zhen $\mathrm{Li} \mathbb{D}^{2,3}$ and Jing Zheng $\mathbb{D D}^{2,3}$ \\ ${ }^{1}$ China Railway Guangzhou Group Co., Ltd., Guangzhou, China \\ ${ }^{2}$ School of Civil Engineering, Department of Bridge Engineering, Southwest Jiaotong University, Chengdu 610031, China \\ ${ }^{3}$ MOE Key Laboratory of High-Speed Railway Engineering, Southwest Jiaotong University, Chengdu 610031, Sichuan, China
}

Correspondence should be addressed to Xiao-Zhen Li; xzhli@swjtu.edu.cn and Jing Zheng; zhengjing927@163.com

Received 10 December 2019; Revised 11 January 2021; Accepted 23 March 2021; Published 23 April 2021

Academic Editor: Chunshun Zhang

Copyright ( 92021 Hao Li et al. This is an open access article distributed under the Creative Commons Attribution License, which permits unrestricted use, distribution, and reproduction in any medium, provided the original work is properly cited.

\begin{abstract}
A field test was conducted to investigate the vibration of the fully enclosed sound barrier (FESB) of a railway bridge, and a numerical method was proposed and validated for evaluating the vibration of the bridge-FESB system by combining the traintrack coupled theory and the motion equation. Additionally, a numerical analysis of the vibration distribution of the FESB was performed. The results indicated that the vibrations of the FESB were mainly caused by the vertical vibration of the bridge under the dynamic wheel-rail interaction with the greatest vibration level from $1 / 4$ to $1 / 2$ part of the steel arch and were not affected by the train position but increased with an increase in the speed of the train.
\end{abstract}

\section{Introduction}

The noise problem caused by rail transit significantly limits the development of rail transit in areas with strict requirements regarding noise. Countermeasures have been taken to reduce the noise, and sound barriers are widely applied as an efficient method. Various sound barriers have been widely adopted alongside urban roads and railways. Traditional upright sound barriers commonly used around schools and factories and in residential areas have a limited noise-reduction effect, because of their simple construction, insufficient heights, and noise diffraction. Increasing the height or changing the shape of the top structure can improve the noise-reduction effect of the upright barriers, but noise can still be transmitted directly from the open top of the sound barrier; thus, these methods are ineffective for high-rise buildings $[1,2]$. The new type of fully enclosed sound barrier (FESB) is tall (above the catenary) and has an enclosed top, which can directly cover the sound inside and achieve the required noise mitigation $[3,4]$. The FESBs comprise steel members, which are connected by bolts and may induce fatigue damage, position movement, large vibrations, and structure-born noise due to passing trains and the vibration of the FESB induced by the corresponding fluctuating pressure and wheel-rail dynamic load generated. Therefore, it is necessary to study the vibration of FESBs to ensure the safety of line operations. When FESBs are installed on the railway bridge, the vibrations generated by the movement of trains are transmitted through rail, track structure, and bridge members and finally to the FESBs. We investigated the vibration characteristics of the FESBs in this case.

This study focuses on the vibration of the FESB under the wheel-rail force, which is the excitation source of the traintrack coupled vibration and can be divided into two parts: the moving axle load (quasi-static load effect) and the dynamic wheel/rail interaction at wheel-rail contact points. According to related literature [5-7], the influence of the quasi-static load on the vibration of the structure under the rail is closely related to the train speed. When the train speed is $<200 \mathrm{~km} / \mathrm{h}$, the quasi-static load only affects the vibration at low frequencies $(<20 \mathrm{~Hz})$ and can be generally considered as a known quantity for vibration analysis. In this study, the vibration of the bridge-FESB system under the dynamic wheel-rail interaction was analyzed. Predictions of the wheel-rail interaction are usually based on the train-track 
dynamic coupling system, with the track roughness as the power source and the vehicle as a multibody system composed of the body, bogie, primary suspension, secondary suspension, and wheelsets, to solve the motion equation of the vehicle, track, and bridges for the coupled system [8-11]. Li et al. [12] used the Newmark- $\beta$ method to solve the motion equation in the time domain and obtained the vibration response of an elevated bridge. Wu and Thompson [13] used the dynamic flexibility method to calculate the frequency-domain vibration response of a box girder bridge. To optimize the prediction models, $\mathrm{Li}$ [14] compared the calculation cost and accuracy of the mode superposition method in the time domain and the power flow model in the frequency domain for the coupled system. Zhang and Xia [15] conducted a dynamic analysis based on the intersystem iteration method. These methods have facilitated the solution of the dynamic equations of the coupled system and are often applied to the environmental vibration and vibration acoustic problems caused by the coupled system. Li and Liang $[16,17]$ studied the effects of different track structures on the vibration and structural noise of an elevated concrete box girder. Song and Li $[9,18]$ compared three measures related to vibration and noise control for an urban rail transit viaduct: a sound barrier, a trackpad with low rigidity, and a floating ladder track. Zhang and Song $[19,20]$ studied the radiated noise of the vibrating box girder bridge via numerical and experimental research. The present study was inspired by the foregoing research.

For FESBs mounted on high-speed railway bridges, a vibration test, theoretical research, and numerical calculations of the FESB were conducted. The theoretical analysis and numerical model were validated by the test results. Finally, the vibration distribution law of the FESB was comprehensively analyzed. The method used in this paper can provide a reference for the vibration analysis of similar trackside structures and can be used for a preliminary study of the acoustic and vibration characteristics of the sound barrier structure.

\section{Field Tests}

2.1. Target FESB. The subject FESBs were mounted on a $32 \mathrm{~m}$ long simply supported box-shaped bridge with a double ballast track along the Shenzhen-Maoming highspeed railway passenger dedicated line, as shown in Figure 1. The major components of the FESB were $\mathrm{H}$ beam steel arches (dimensions: $330 \mathrm{~mm} \times 300 \mathrm{~mm} \times 10 \mathrm{~mm} \times 15 \mathrm{~mm}$ ) arranged at $2 \mathrm{~m}$ intervals with a radius of $6.45 \mathrm{~m}$. Longitudinal bracings with a square section (dimensions: $80 \mathrm{~mm} \times 80 \mathrm{~mm}$ ) were arranged at $4 \mathrm{~m}$ intervals along the circumferential direction of the steel arches, connecting all arch rings along the length of the bridge. Metal sound insulation plates were embedded between the adjacent arches. The metal unit plates were $0.140 \mathrm{~m}$ thick, $2 \mathrm{~m}$ long, and $0.5 \mathrm{~m}$ wide. The bridge below the FESB is simply a supported box girder bridge. The total height was $3.09 \mathrm{~m}$, and the widths of the deck and bottom slab were 12 and $5.5 \mathrm{~m}$, respectively. The dual ballast track was laid on the bridge and consisted of a rail, fasteners, reinforced-concrete sleepers, and trackbed. For convenience, the right line in Figure 1(b) is denoted as the upbound line, and the left line is denoted as the downbound line. The FESBs are arc-shaped and have a long distribution along the bridge length; hence, the vibrations of the FESB are mainly along the radial direction, and the vibrations of bridge members under the action of wheel-rail excitation are mainly in the vertical direction. The vertical vibration of the bridge and the radial vibration of the FESB are discussed later in this paper.

2.2. Outline of Measurement Points. Field measurements were performed to obtain the vibration responses of the FESB. During the measurements, three variables were continuously recorded: the train speeds, upbound or downbound line, and the vibration acceleration signals. 10 accelerometers (V1-V10; CA-YD-181 piezoelectric type) were installed on the FESB at the midspan of the bridge, as shown in Figure 2. $V 1, V 2$, and $V 3$ were close to the upbound line and arranged on the middle steel arch of the FESB at heights of 7.3, 4.45, and $1.5 \mathrm{~m}$, respectively, from the root of the SESB. These values are identical to the heights of the upper edges of plates No. 1, No. 7, and No. 13, respectively. $V 4, V 5$, and $V 6$ were located in the middle of these three plates, respectively. $V 7$ was installed in the opposite position to $V 1 . V 8, V 9$, and $V 10$ were arranged under the rail, the top deck, and the bottom board of the box girder, respectively.

The field test was conducted during normal line operation. More than 100 sets of data were obtained on double lines of the railway at an average speed of approximately $100 \mathrm{~km} / \mathrm{h}$. The transit trains were mainly CRH380A and CRH380B, marshaled by two motor vehicles with six trailers. The upper limit cutoff frequency of the vibration signals in the field test was $5000 \mathrm{~Hz}$. The sampling frequency should exceed twice the highest frequency $F_{\max }$ in the signal according to the Nyquist sampling theorem and should exceed $(2.56-4) \times 2 \times \mathrm{F}_{\max }$ according to the general engineering requirements. Therefore, an INV3060S dynamic data-acquisition instrument with a sampling frequency of $25.6 \mathrm{kHz}$ was adopted. A preliminary analysis was conducted to eliminate abnormal data before data processing.

\subsection{Test Results}

2.3.1. Results in Time Domain. The time histories of the vibration acceleration at measurement points $V 8$ (under the rail) and $V 9$ (on the top plate of the box girder) are plotted in Figure 3, where the background vibration and train-induced vibration can be clearly distinguished. In Figure 3(a), there were eight peaks caused by the wheelsets of the passing train. The speed of the passing train was calculated using the train length and time. The acceleration of the rail ranged from -365 to $368 \mathrm{~m} / \mathrm{s}^{2}$. The approximate time taken by each wheelset to pass over the bridge was easily determined from the results for the top board of the bridge in Figure 3(b). The vibration acceleration of the top plate was in the range of -1.72 to $1.78 \mathrm{~m} / \mathrm{s}^{2}$. The vibration of the bottom board was slightly smaller than that of the top plate, whose acceleration ranged from -1.43 to $1.43 \mathrm{~m} / \mathrm{s}^{2}$. 


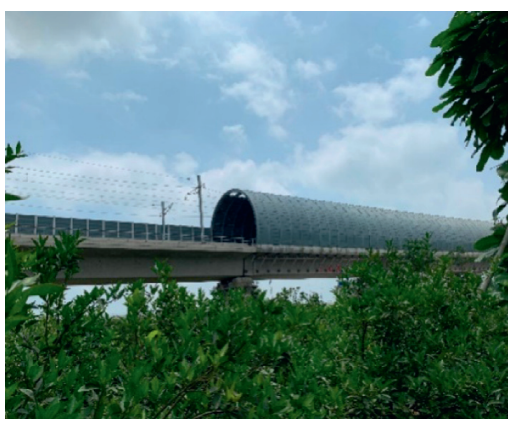

(a)

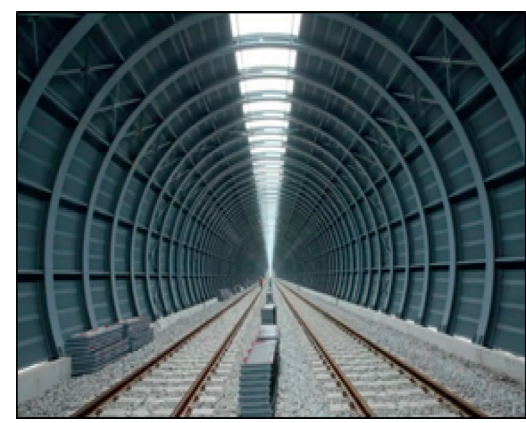

(b)

Figure 1: The FESB.
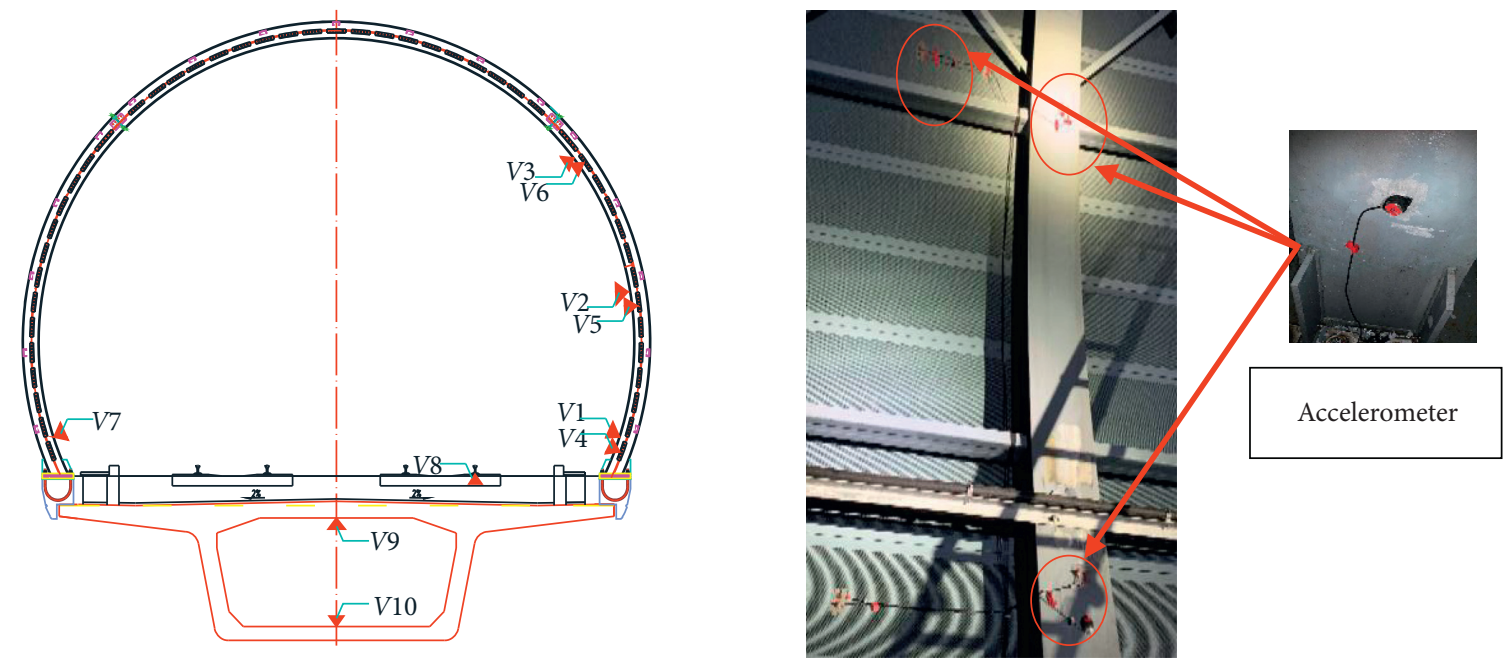

Figure 2: Test diagram of the FESB.

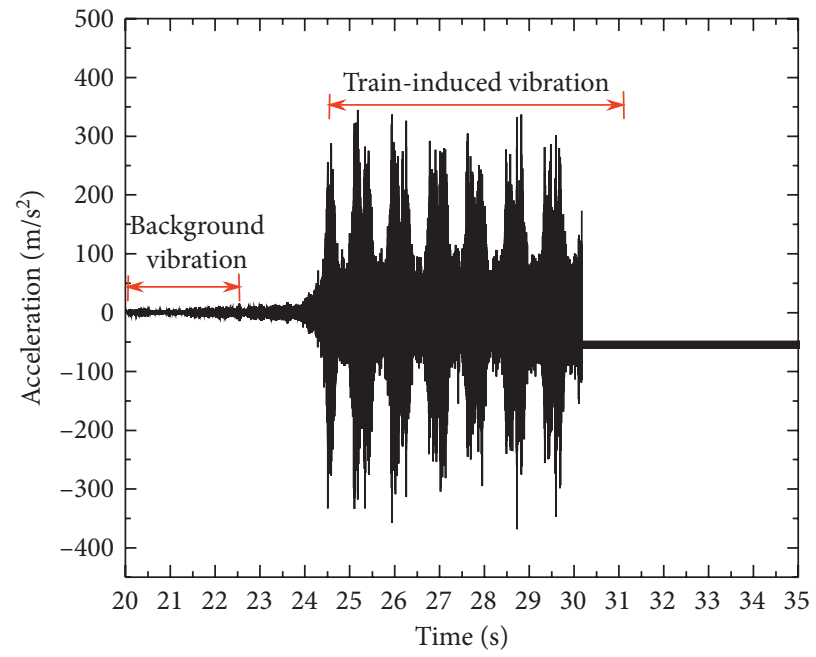

$-V 8$

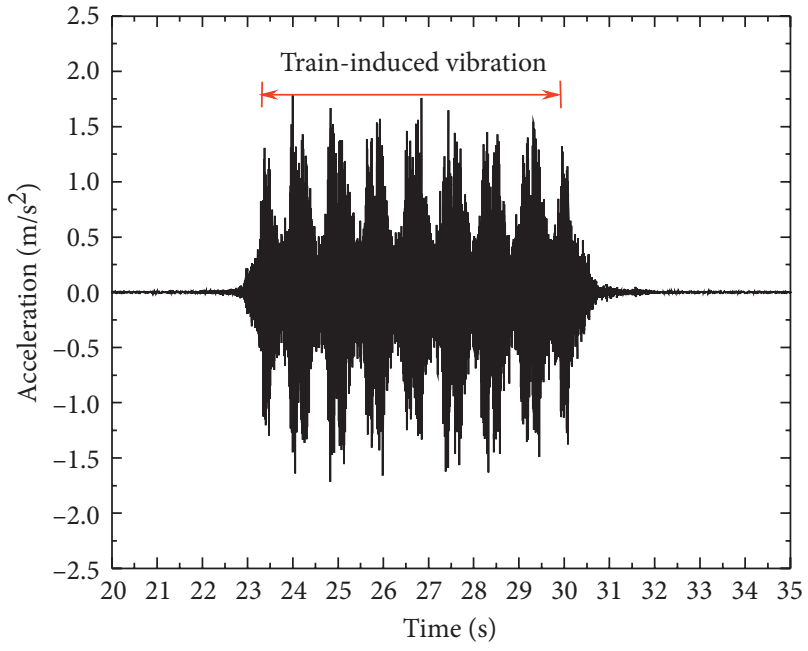

- V9

(a)

(b)

Figure 3: Vibration acceleration time history of (a) the rail and (b) the top board of the bridge. 
Figure 4 shows the acceleration response for each measurement point on the steel arch of the FESB. The results indicate the time of each wheelset passing. The vibration acceleration at point $V 1$ ranged from -1.32 to $1.32 \mathrm{~m} / \mathrm{s}^{2}$ (Figure $4(\mathrm{a})$ ), that at $V 2$ ranged from -1.32 to $1.32 \mathrm{~m} / \mathrm{s}^{2}$, and that at $V 3$ ranged from -1.50 to $1.20 \mathrm{~m} / \mathrm{s}^{2}$ (Figure $4(\mathrm{~b})$ ).

The vibration time histories for the measurement points on the sound insulation plates of the FESB are shown in Figure 5. The vibration acceleration of the element plate at point $V 4$ ranged from -1.95 to $1.89 \mathrm{~m} / \mathrm{s}^{2}$ (Figure $5(\mathrm{a})$ ), and that at $V 6$ ranged from -2.80 to $3.07 \mathrm{~m} / \mathrm{s}^{2}$ (Figure $5(\mathrm{a})$ ). Clearly, the vibrations of the sound insulation plates exceeded those on the steel arch ring, and the vibration response of the sound insulation plates at the arch foot was smaller than that at a higher position.

The background vibration for point V8 (Figure 3(a)) exceeded that for point $V 9$ (Figure 3(b)). This is because the rigidity of the rail was lower than that of the bridge. The background vibration for point $V 1$ in Figure 4(a) was smaller than that for point $V 3$ in Figure 4(b). This is because $V 1$ was closer to the fixed constraint end, which was also the case for points $V 4$ and $V 6$, as shown in Figure 5.

2.3.2. Results in Frequency Domain. Figure 6 shows the spectral distribution of the vibration acceleration of the rail and the top board of the bridge. As shown in Figure 6(a), the vibration of the rail was the largest in the frequency range of $1200-1500 \mathrm{~Hz}$, with a peak value at approximately $1300 \mathrm{~Hz}$, and there were two smaller peaks below $1000 \mathrm{~Hz}$ (around 470 and $960 \mathrm{~Hz}$ ). As shown in Figure 6(b), the vibrations of the top board were mainly below $1000 \mathrm{~Hz}$, with peak and subpeak frequencies of approximately 477 and $63 \mathrm{~Hz}$ and a large vibration fluctuation at approximately $960 \mathrm{~Hz}$. The vibration of the bottom plate was similar to that of the top plate, with peak frequencies of approximately 63, 477, and $960 \mathrm{~Hz}$.

The vibration spectra of the steel arch ring of the FESB are shown in Figure 7. The outstanding vibration frequency at all the measurement points on the steel arch was approximately $470 \mathrm{~Hz}$, and the vibrations were densely distributed in the low-frequency range of $60-250 \mathrm{~Hz}$. For the acceleration value, the vibration at point $V 3$ was higher than that at $V 1$ in the low-frequency range, but the opposite was observed at $470 \mathrm{~Hz}$.

The vibrations on the sound insulation plates of the FESB are shown in Figure 8. They were concentrated below $100 \mathrm{~Hz}$, with a peak value of approximately $70 \mathrm{~Hz}$. The peak value for point $V 6$ exceeded that for $V 3$, and the vibrations on the sound insulation plates were significantly larger than those on the steel arch.

The $1 / 3$ octave band is another type of spectrum analysis method that has fewer spectral lines and a relatively wide frequency band, accurately reflecting the distribution of the vibration energy. In Figure 9, the vibration accelerometer level (VAL) is plotted by the $1 / 3$ octave band according to the vibration test results for each measurement point. The outstanding VAL of the rail in Figure 9(a) ranges from 1000 to $1600 \mathrm{~Hz}$, and the vibration fluctuated around 50, 200, and $400 \mathrm{~Hz}$. The peak value for the top board of the bridge illustrated in Figure 9(b) occurred at $400 \mathrm{~Hz}$, and other large vibrations occurred at $50,160,400$, and $800 \mathrm{~Hz}$. The vibration distribution of the bottom board was similar to that of the top board. The VALs of the measurement points on the steel arch ring plotted in Figures 9(c)-9(e) were mainly distributed in the frequency range of $50-500 \mathrm{~Hz}$. Here, the peak value at $V 1$ occurred at $400 \mathrm{~Hz}$, and the VAL gradually decreased upward along the steel arch ring. The spectrum characteristics of the vibration at the measurement point on the opposite side of the steel arch were similar to those near the upbound line. Compared with the steel arch, the vibration on the sound insulation plates was rapidly attenuated above $63 \mathrm{~Hz}$, as shown in Figure 9(f). The peak VAL was significantly larger than that of the steel arch ring.

The spectrum characteristics of the radial vibration of the steel arch on the FESB were consistent with the vertical vibration of the bridge. This is because the lateral stiffness of the bridge exceeded the vertical stiffness, the lateral vibrations of the bridge were significantly smaller than the vertical vibrations, and the contribution of the lateral vibrations of the bridge to the lateral vibration of the FESB was small. Hence, the vibration of the FESB was mainly related to the vertical vibration of the bridge structure, which originated from the vibration of the rail due to the movement of trains.

\section{Related Theory and Numerical Model}

3.1. Coupled Model of Train-Ballasted Track. The ballasted track consists of a rail, a fastener, concrete sleepers, and a trackbed. In this study, only the vertical vibration was considered, and a three-layer continuous elastic support model of half of a ballasted track is established, as shown in Figure 10. The rail is simplified as an Euler beam with infinite length; the sleepers and trackbed are regarded as rigid bodies, the bridge is regarded as a rigid foundation; and the connections among the rails, sleepers, trackbed, and foundation are modeled using spring-damper elements.

The harmonic force acting on the rail in Figure 10 is denoted as $F e^{i \omega t}$, where $F$ represents the amplitude of the force, $i$ represents the imaginary unit, $\omega$ represents the circular frequency, and $t$ represents time. In the time domain, the motion equations of the rail, sleepers, and trackbed are as follows:

$$
\begin{aligned}
\rho_{r} A_{r} \frac{\partial^{2} x_{r}}{\partial t^{2}}+E_{r}^{*} I_{r} \frac{\partial^{4} x_{r}}{\partial z^{4}}+k_{p}^{*}\left(x_{r}-x_{s}\right) & =F e^{i \omega t} \delta(z), \\
m_{s} \frac{\partial^{2} x_{s}}{\partial t^{2}}+\left(k_{p}^{*}+k_{b}^{*}\right) x_{s}-k_{p}^{*} x_{r}-k_{b}^{*} x_{b} & =0 \\
m_{b} \frac{\partial^{2} x_{b}}{\partial t^{2}}+\left(k_{b}^{*}+k_{f}^{*}\right) x_{b}-k_{b}^{*} x_{s} & =0
\end{aligned}
$$

where $\rho_{r}, A_{r}$, and $I_{r}$ represent the density, sectional area, and moment of inertia of the rail, respectively; $E_{r}^{*}=E_{r}\left(1+i \eta_{r}\right)$ represents the complex elastic modulus of the rail; $\eta_{r}$ 


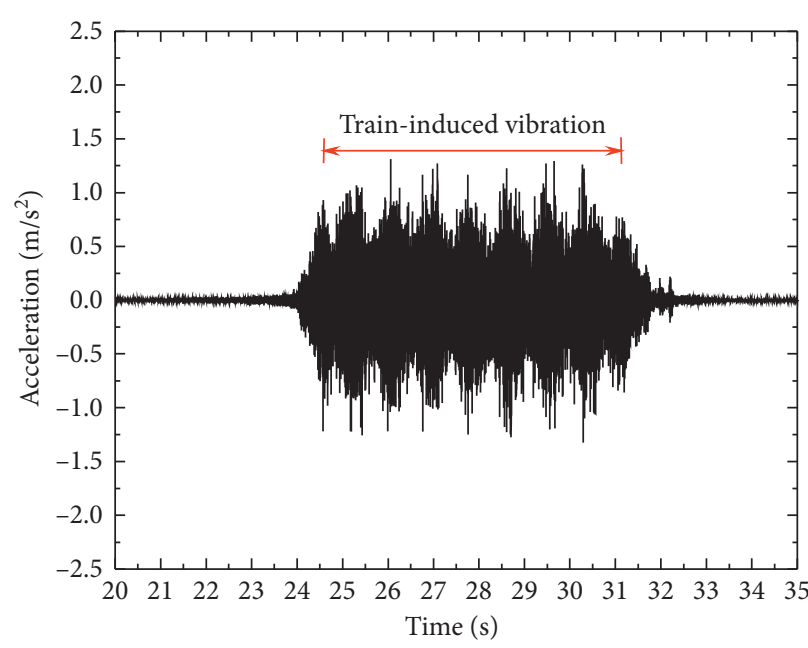

$-V 1$

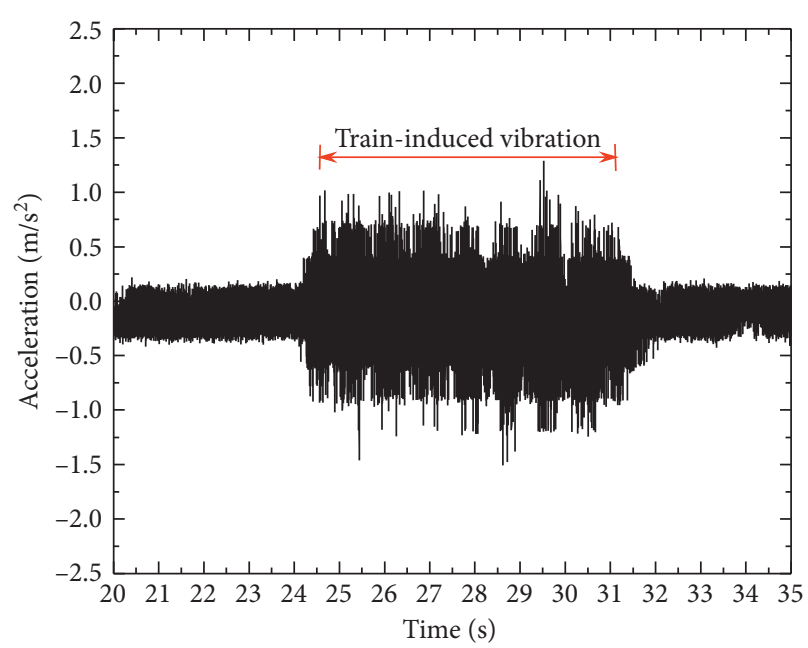

$-V 3$

FIgURE 4: Vibration time histories for points (a) $V 1$ and (b) $V 3$ on the steel arch ring.

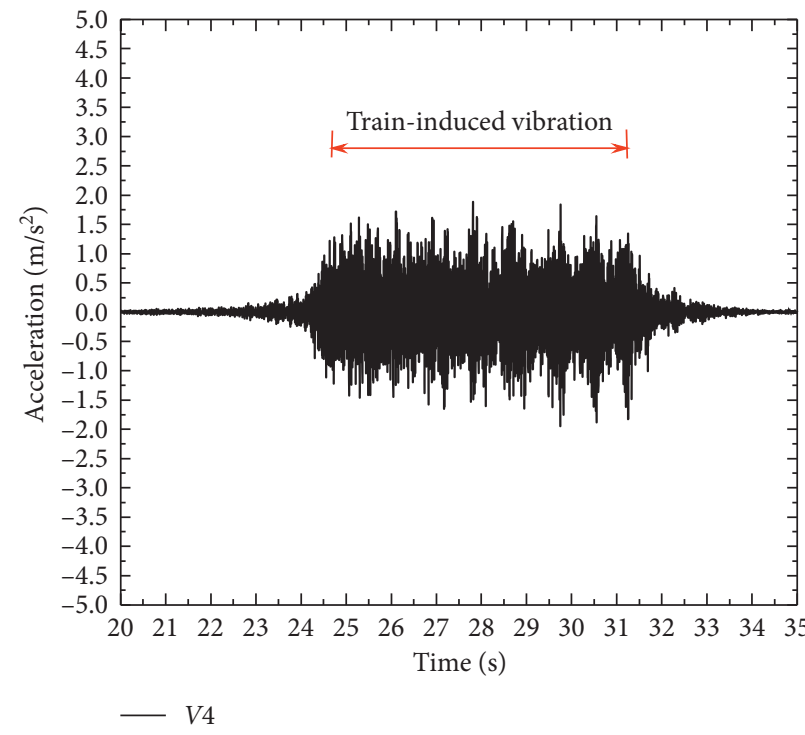

(a)

Figure 5: Vibration time histories for points

represents the loss factor of the rail; $\delta$ represents the Dirac function; $m_{s}$ and $m_{b}$ represent the masses of the sleeper and ballast (converted to meters), respectively; $x_{r}, x_{s}$, and $x_{b}$ represent the displacements of the rail, sleeper, and ballast bed, respectively. $k_{p}^{*}=k_{p}\left(1+i \eta_{p}\right), k_{b}^{*}=k_{b}\left(1+i \eta_{b}\right)$, and $k_{f}^{*}=k_{f}\left(1+i \eta_{f}\right)$ represent the supporting complex stiffness of the fasteners, trackbed, and foundation (per meter), respectively, where $\eta_{p}, \eta_{b}$, and $\eta_{f}$ represent the loss factors of the fastener, trackbed, and foundation, respectively.

The steady-state responses of the rail, sleepers, and ballast bed are denoted as $x_{r}=X_{r} e^{i \omega t} x_{s}=X_{s} e^{i \omega t}$, and $x_{b}=X_{b} e^{i \omega t}$, respectively, where $X r, X s$, and $X_{b}$ represent the vibration

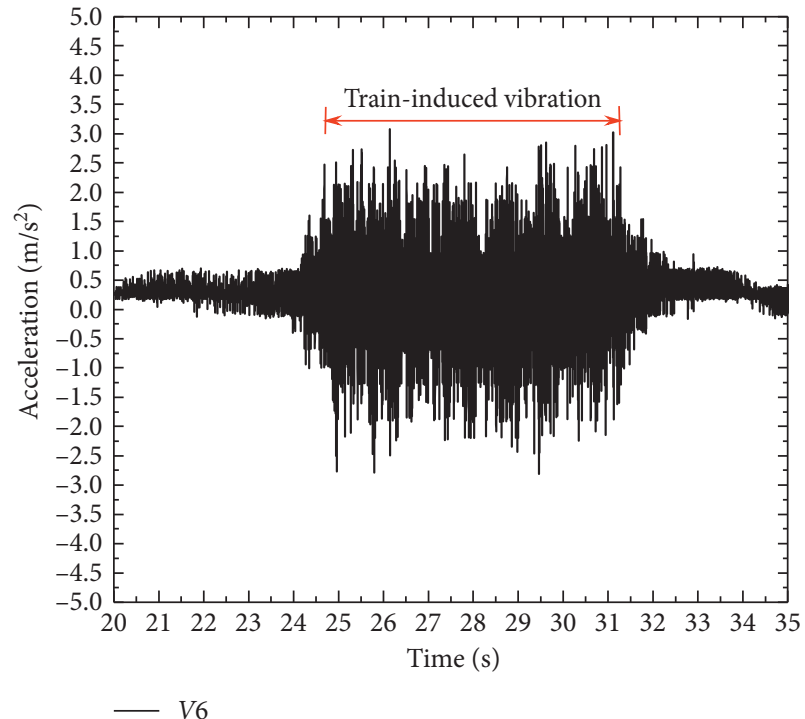

(b)

(a) V4 and (b) V6 on the sound insulation plates.

amplitudes. The frequency-domain motion equations corresponding to equations (1)-(3) are as follows:

$$
\begin{aligned}
-\rho_{r} A_{r} \omega^{2} X_{r}+E_{r}^{*} I_{r} X_{r}^{\prime \prime \prime}+k_{p}^{*}\left(X_{r}-X_{s}\right) & =F \delta(z), \\
-k_{p}^{*} X_{r}+ & \left(k_{p}^{*}+k_{b}^{*}-m_{s} \omega^{2}\right) X_{s}-k_{b}^{*} X_{b}=0, \\
-k_{b}^{*} X_{s}+\left(k_{b}^{*}+k_{f}^{*}-m_{b} \omega^{2}\right) X_{b} & =0 .
\end{aligned}
$$

By applying the Laplace transform and residue method to equations (4)-(6), the displacement response of each component of the ballasted track is determined as follows: 


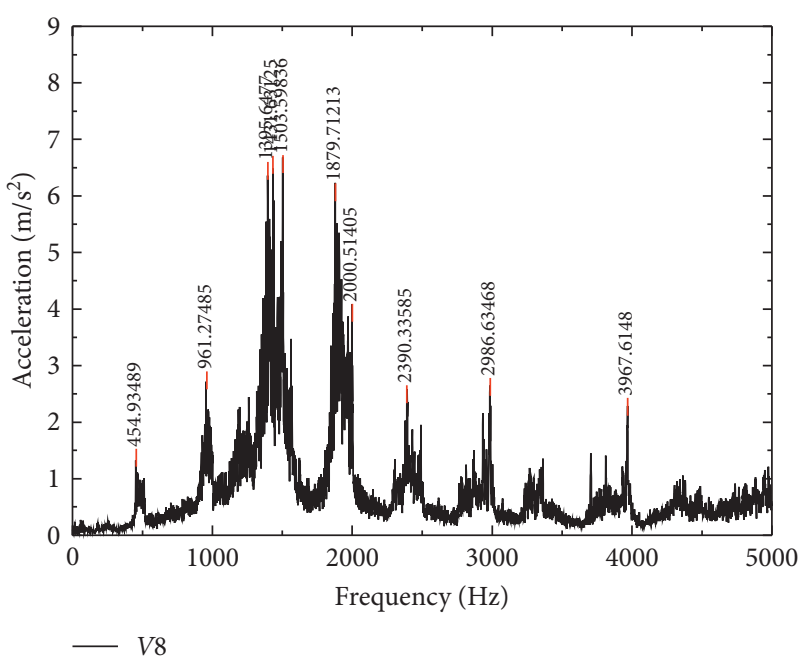

(a)

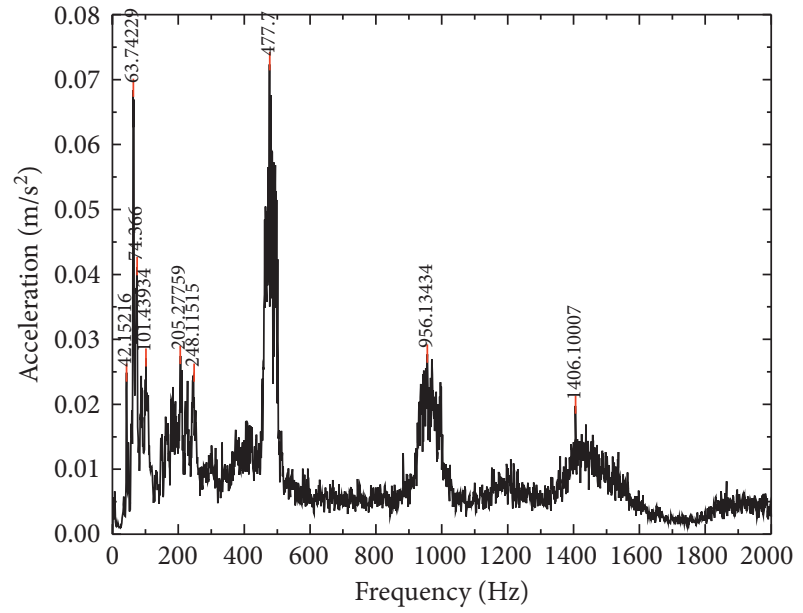

V9

FIgURe 6: Vibration spectra of the (a) rail and (b) top board of the box girder.

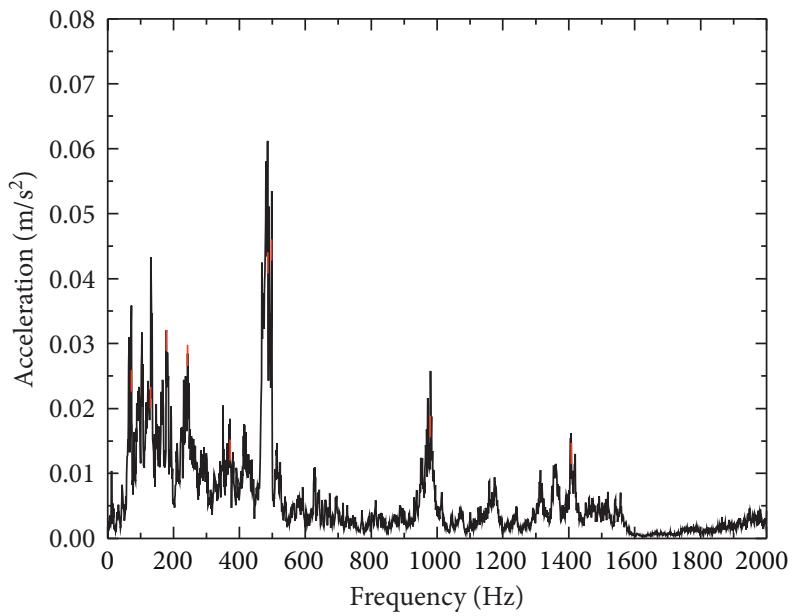

(a)

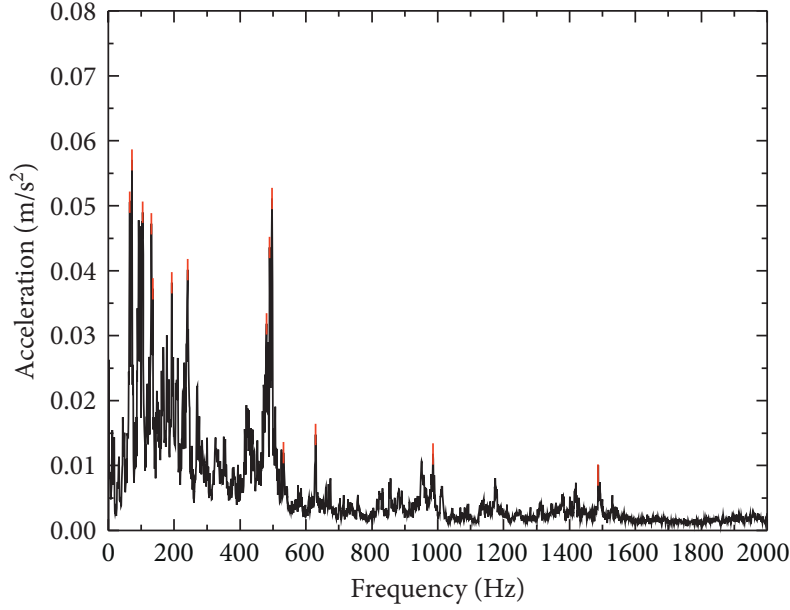

(b)

FIgURE 7: Vibration spectra for points (a) V1 and (b) $V 3$ on the steel arch.

$$
\begin{aligned}
X_{r} & =\frac{-i F}{4 E_{r}^{*} I_{r} k^{3}}\left(e^{-i k\left|z-z_{1}\right|}-i e^{-k\left|z-z_{1}\right|}\right), \\
X_{s} & =\frac{\left(k_{b}^{*}+k_{f}^{*}-m_{b} \omega^{2}\right) k_{p}^{*}}{\left[\left(k_{p}^{*}+k_{b}^{*}-m_{s} \omega^{2}\right)\left(k_{b}^{*}+k_{f}^{*}-m_{b} \omega^{2}\right)-\left(k_{b}^{*}\right)^{2}\right]} X_{r}, \\
X_{b} & =\frac{k_{b}^{*}}{k_{b}^{*}+k_{f}^{*}-m_{b} \omega^{2}} X_{s}, \\
k & =\left(\frac{\rho_{r} A_{r} \omega^{2}-k_{e q}}{E_{r}^{*} I_{r}}\right)^{0.25},
\end{aligned}
$$$$
k_{e q}=\frac{k_{p}^{*}\left[\left(k_{b}^{*}+k_{f}^{*}-m_{b} \omega^{2}\right)\left(k_{b}^{*}-m_{s} \omega^{2}\right)-\left(k_{b}^{*}\right)^{2}\right]}{\left[\left(k_{p}^{*}+k_{b}^{*}-m_{s} \omega^{2}\right)\left(k_{b}^{*}+k_{f}^{*}-m_{b} \omega^{2}\right)-\left(k_{b}^{*}\right)^{2}\right]},
$$

where $z$ represents the action position of harmonic force, $z_{1}$ represents the investigating position, $k$ represents the rail wave number, and $k_{\text {eq }}$ represents the equivalent stiffness of the fastener-sleeper-trackbed system.

3.2. Wheel-Rail Interaction. In the simplified wheel-rail model shown in Figure 11, the wheel-rail contact is simplified as linear Hertz contact, and the sum of the wheel 


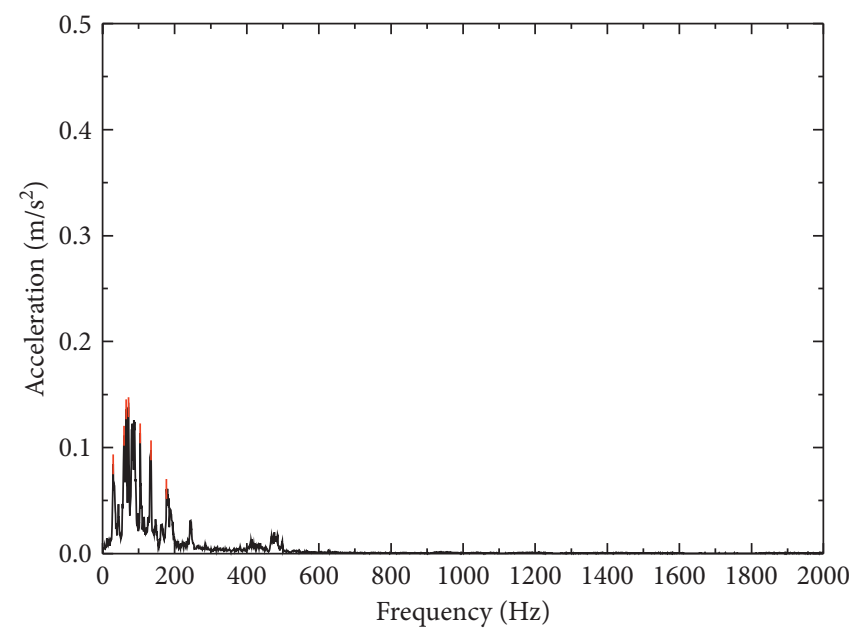

(a)

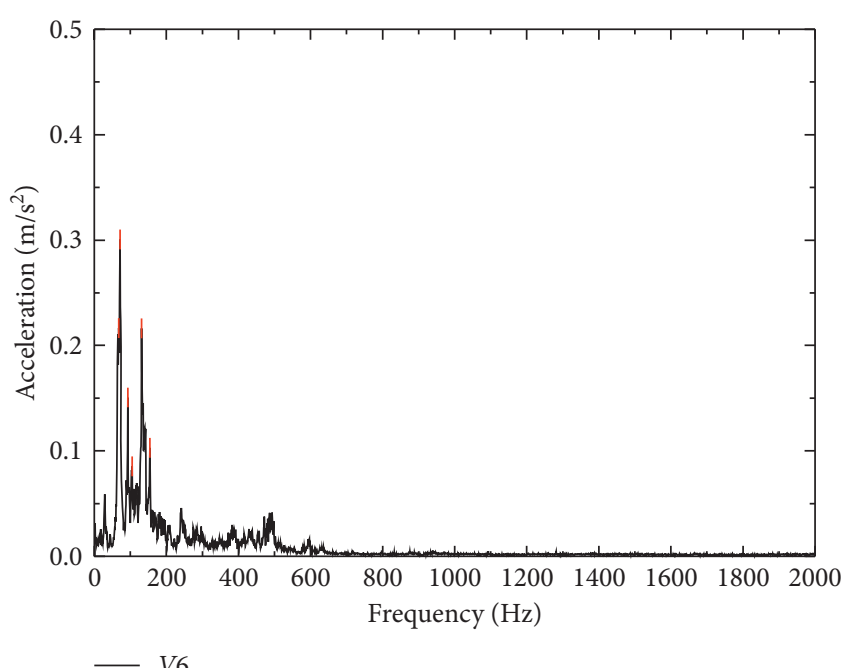

(b)

FIgURE 8: Vibration spectra for points (a) V4 and (b) V6 on the sound insulation plates.

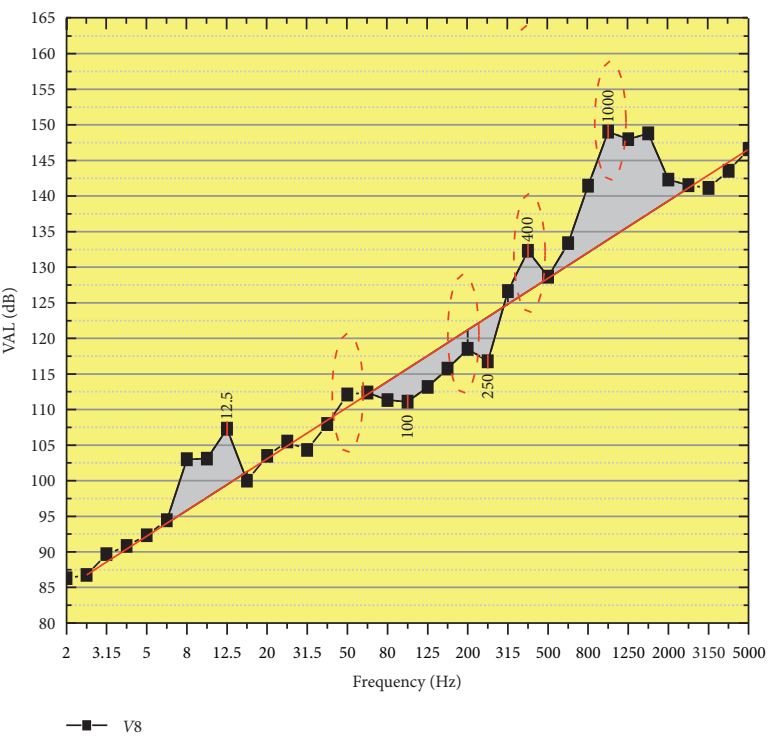

(a)

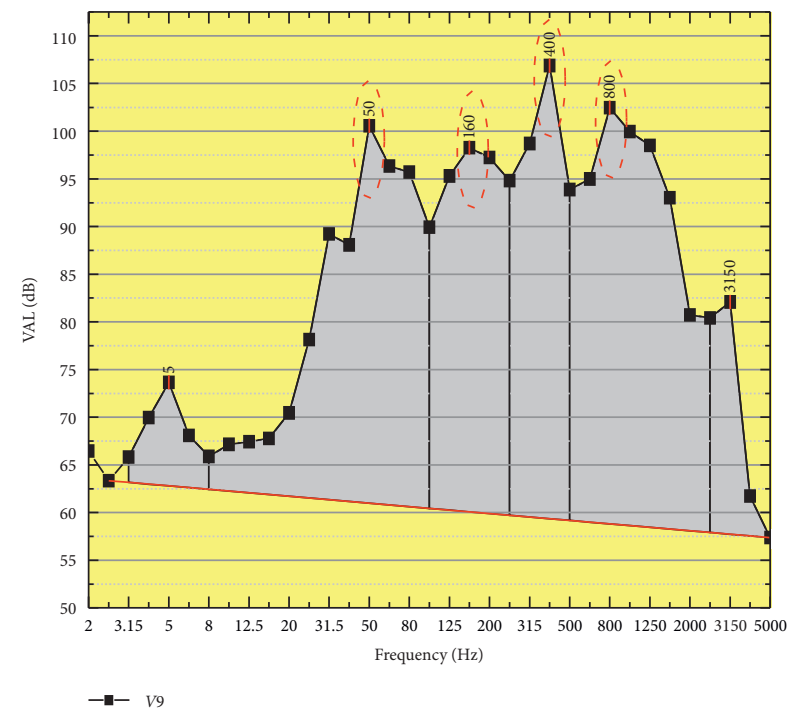

(b)

Figure 9: Continued. 


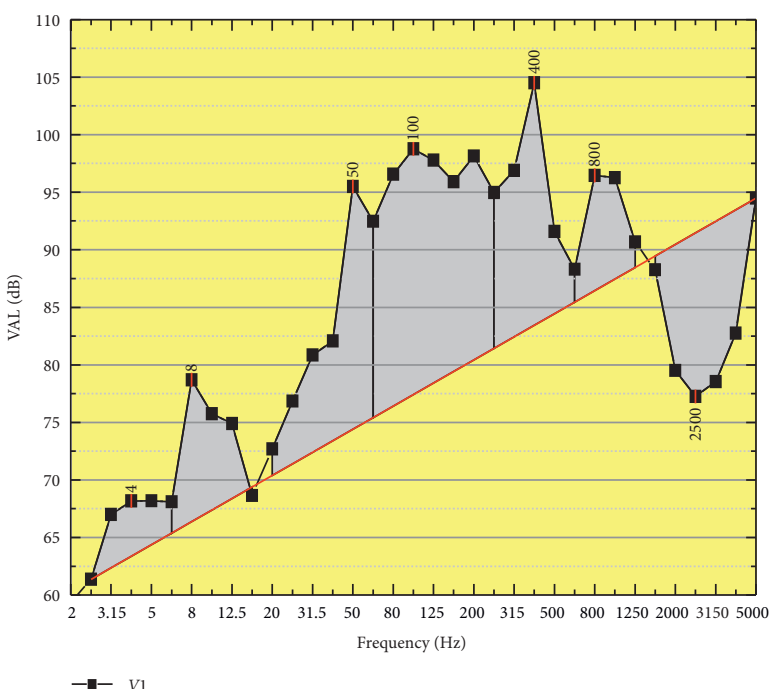

(c)

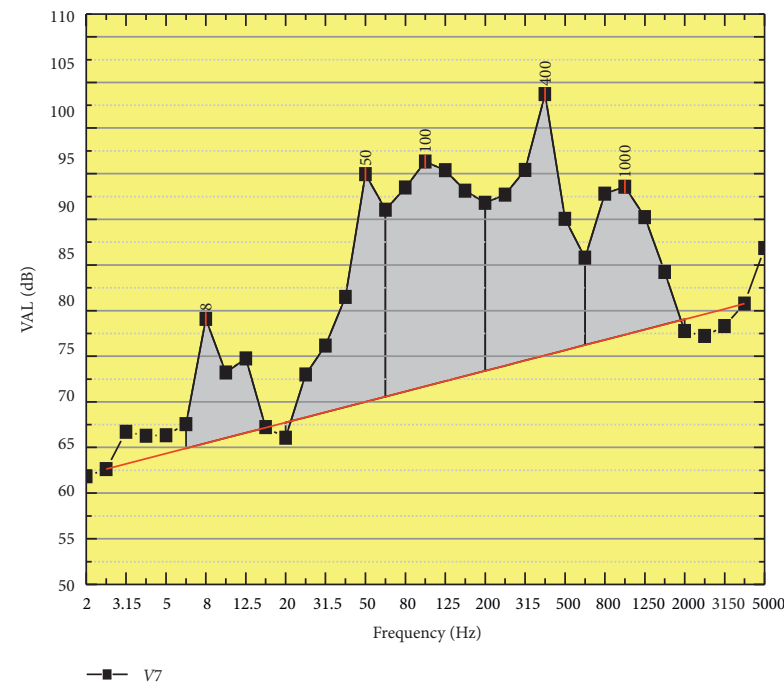

(e)

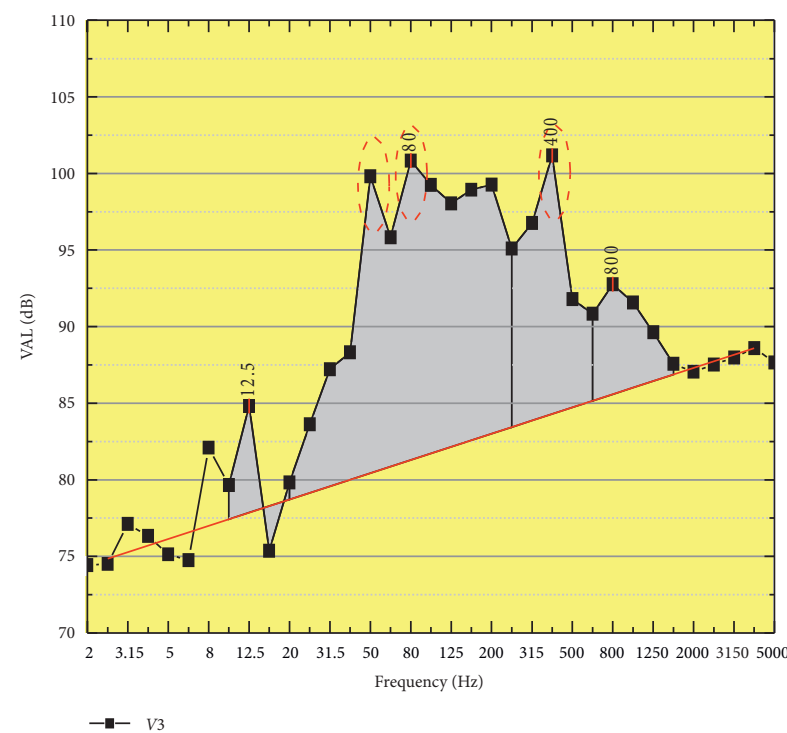

(d)

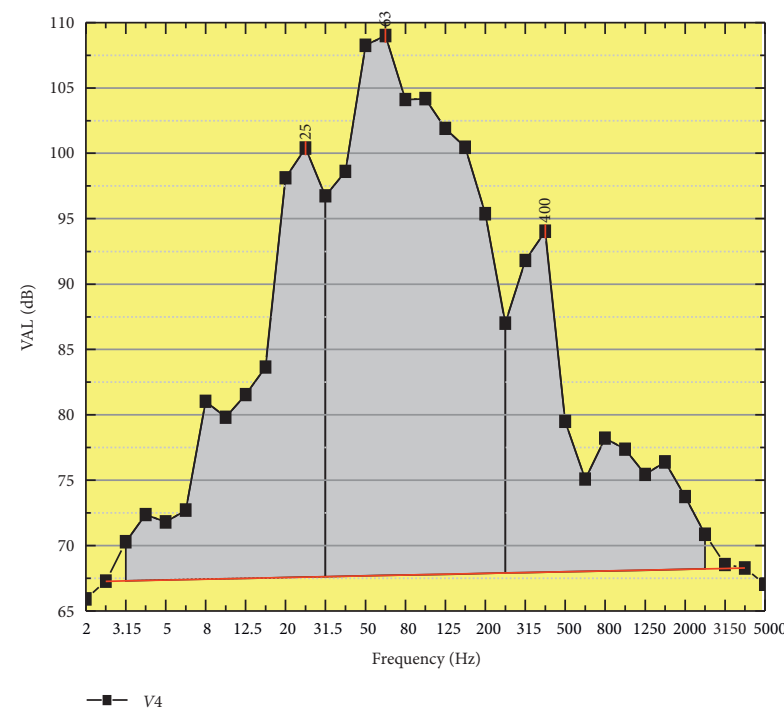

(f)

Figure 9: 1/3-octave analysis of the bridge-FESB system.

dynamic flexibility, wheel-rail linear contact flexibility, and track dynamic flexibility affects the wheel-rail force. Therefore, according to the dynamic flexibility method, the wheel-rail force in the frequency domain can be determined as follows [5]:

$$
F_{w / r}=\frac{-\Delta}{\alpha^{w}+\alpha^{c}+\alpha^{t}},
$$

where $F_{w / r}$ represents the wheel-rail force; $\Delta$ represents the track irregularity; $\alpha^{\mathrm{w}}, \alpha^{\mathrm{c}}=1 / k_{\mathrm{H}}$, and $\alpha^{\mathrm{r}}$ represent the wheel dynamic flexibility, wheel-rail linear contact flexibility, and track dynamic flexibility, respectively; and $k_{H}$ represents the stiffness of the Hertz contact.

The wheel dynamic flexibility is calculated as follows [7]:

$$
\alpha^{w}=\frac{k_{1}+i \omega c_{1}-m_{b} \omega^{2}}{m_{w} m_{b} \omega^{4}-\left(k_{1}+i \omega c_{1}\right)\left(m_{w}+m_{b}\right) \omega^{2}},
$$

where $k_{1}$ and $c_{1}$ represent the stiffness and damping coefficient, respectively, of the vehicle primary suspension; $m_{\mathrm{w}}$ represents the mass of the wheel and its nonsuspension; $m_{\mathrm{b}}$ represents $1 / 4$ mass of the bogie.

The dynamic flexibility of the track describes the displacement of the rail at the action point of the harmonic force on the rail and can be determined using

$$
\alpha^{t}=\frac{-1-i}{4 E_{r}^{*} I_{r} k^{3}} .
$$




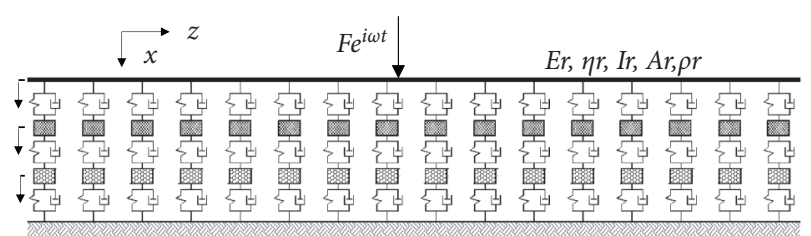

Figure 10: Three-layer-continuous elastic support model of $1 / 2$ ballasted track.

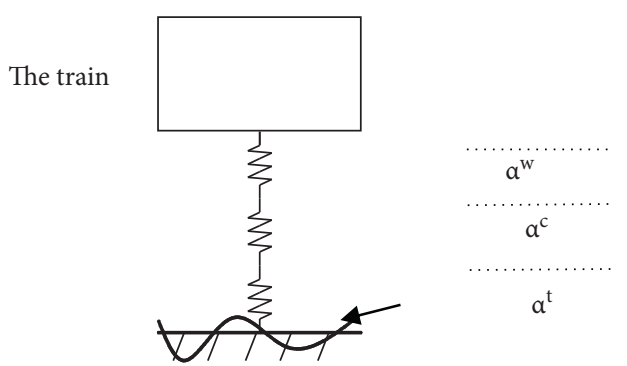

FIGURE 11: Wheel-rail interaction model.

3.3. Bridge-FESB Model. A finite-element (FE) model of the bridge-FESB system was established according to the actual design dimensions of the bridge and the barrier, as shown in Figure 12. The members of the box girder and $\mathrm{H}$-shaped steel arches are modeled using the shell element to investigate their local vibrations at medium and high frequencies. The connections between the roots of steel studs and the flange slabs of the box girder are treated as common nodes. Longitudinal braces are modeled using a two-node spatial beam element. The measured vibrations of the components of the bridge-FESB system are mostly $<1000 \mathrm{~Hz}$, which is the cutoff frequency for the numerical calculations in this study. To ensure the accuracy of the numerical results, the maximum cell size of the model should be $<1 / 6$ of the minimum wavelength of the bending vibration of the shell. $C_{b}$ is calculated using the following formula:

$$
C_{b}=\left(\frac{E h^{2}}{12 \rho\left(1-\mu^{2}\right)}\right)^{0.25} \sqrt{\omega} .
$$

The main physical parameters for the materials of the bridge and sound barrier are presented in Table 1. For satisfying the calculation requirements, the maximum element size of the model should not exceed $0.39 \mathrm{~m}$.

3.4. Validation. The dynamic wheel-rail force of the ballast track and the acting positions of the wheels are calculated using MATLAB. The FE model presented in Section 3.2 is used to analyze the vibration acceleration of the bridgeFESB system. In accordance with the field measurements, a CRH380A-type train traveling on the upbound line at a speed of $110 \mathrm{~km} / \mathrm{h}$ is considered. The recommended value in ISO 3095:2005 is adopted for the track irregularity spectrum. Elastic strip type-IV fasteners and type-III reinforced-concrete sleepers are applied to the rail line. The relevant parameters involved in the numerical calculations are presented in Table 2.

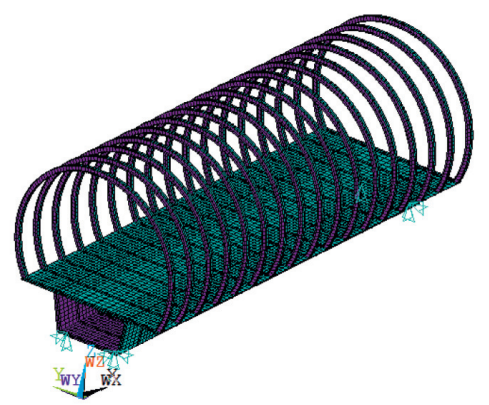

Figure 12: FE model of the bridge-FESB system.

The VALs for measurement points $V 1, V 2, V 3$, and $V 9$ are plotted in Figure 13 for the $1 / 3$ octave band. As shown, the spectrum compositions and vibration trends are consistent between the calculations and measurements (with the former results being slightly higher) even though they are influenced by multiple parameters. This numerical model is validated to be used for further numerical analysis and studying the vibration law of the FESB.

\section{Further Discussion}

4.1. Modal Analysis. A modal analysis was performed using the validated FE model of the bridge-FESB system, and the main vibration modes in the vertical and radial directions are presented in Table 3. As indicated by the table, the whole bridge vibrates until the first vertical bending occurs at $4.8 \mathrm{~Hz}$. At the time, the arch of the fully closed sound barrier vibrates laterally with the whole bridge. The local vibration of the bridge structure begins at $31.6 \mathrm{~Hz}$, and when the local vibration of the flange boards of the box girder occurs, the in-plane vibration of the steel arch on the FESB occurs as well. Additionally, the vibration peak appears at the position of the 1/4-1/2 arch ring, and the high-order local vibration of the bridge members occurs above $300 \mathrm{~Hz}$. When the highorder local vibration occurs, the vibrations on the steel arches are consistent at different positions, and torsion occurs in addition to the in-plane bending.

4.2. Vibration Law of Steel Arch. The steel arch of the FESB is divided into eight equal parts as shown in Figure 14, and the arch foot, $1 / 4$ arch, 1/2 arch, $3 / 4$ arch, and vault are selected as the monitoring points to investigate the radial vibration law of the steel arch in the midspan section. The upbound measurement points are labeled with a " $U$," the downbound points are labeled with a " $D$," and the measurement point of the vault is labeled as "M0." The VALs for the different measurement points are shown in Figure 15.

As shown in Figure 15(a), the VALs for the upbound five points $\mathrm{U} 1-\mathrm{U} 4$ and $\mathrm{M} 0$ are relatively close to each other at the central frequency of $400 \mathrm{~Hz}$. At $50 \mathrm{~Hz}$, the vibrations at the $1 /$ 4 arch and 1/2 arch are larger, whereas those at the arch foot and $3 / 4$ arch are smaller. 
TABLE 1: Material properties of SESB.

\begin{tabular}{lcccc}
\hline Material & $\mathrm{E}\left(\mathrm{N} / \mathrm{m}^{2}\right)$ & Poisson ratio & Density $\left(\mathrm{kg} / \mathrm{m}^{3}\right)$ & Damping ratio \\
\hline Steel & $2.06 \times 10^{11}$ & 0.3 & 7850 & 0.010 \\
Concrete & $3.25 \times 10^{10}$ & 0.2 & 2400 & 0.030 \\
\hline
\end{tabular}

TABLe 2: Calculation parameters.

\begin{tabular}{|c|c|c|c|c|c|}
\hline \multirow{5}{*}{ CRH380 A } & bogie mass $(\mathrm{kg})$ & 3060 & \multirow{2}{*}{ fastener } & stiffness $(\mathrm{N} / \mathrm{m})$ & $6.6 e 7$ \\
\hline & Wheelset mass $(\mathrm{kg})$ & 1517 & & Loss factor & 0.25 \\
\hline & Primary suspension stiffness $(\mathrm{N} / \mathrm{m})$ & $1.772 e 6$ & \multirow{3}{*}{ Sleeper } & Spacing $(\mathrm{m})$ & 0.6 \\
\hline & Primary suspension damping $(\mathrm{N} \bullet \mathrm{s} / \mathrm{m})$ & $2 e 4$ & & $1 / 2$ quality $(\mathrm{kg})$ & 170 \\
\hline & Wheel-rail contact stiffness $(\mathrm{N} / \mathrm{m})$ & $1.4 e 9$ & & Elastic modulus $(\mathrm{Pa})$ & $1.1 e 8$ \\
\hline \multirow{4}{*}{ Rail (CHN60) } & Elastic modulus $(\mathrm{Pa})$ & $2.1 e 11$ & \multirow{4}{*}{ Ballast bed } & Support stiffness $(\mathrm{N} / \mathrm{m})$ & $1.38 e 8$ \\
\hline & Moment of inertia $\left(\mathrm{m}^{4}\right)$ & $3.2 e-5$ & & Loss factor & 1.0 \\
\hline & Density $\left(\mathrm{kg} / \mathrm{m}^{3}\right)$ & $7.85 e 3$ & & & 531.4 \\
\hline & Sectional area $\left(\mathrm{m}^{2}\right)$ & $7.745 e-3$ & & vibration mass (kg) & 531.4 \\
\hline
\end{tabular}

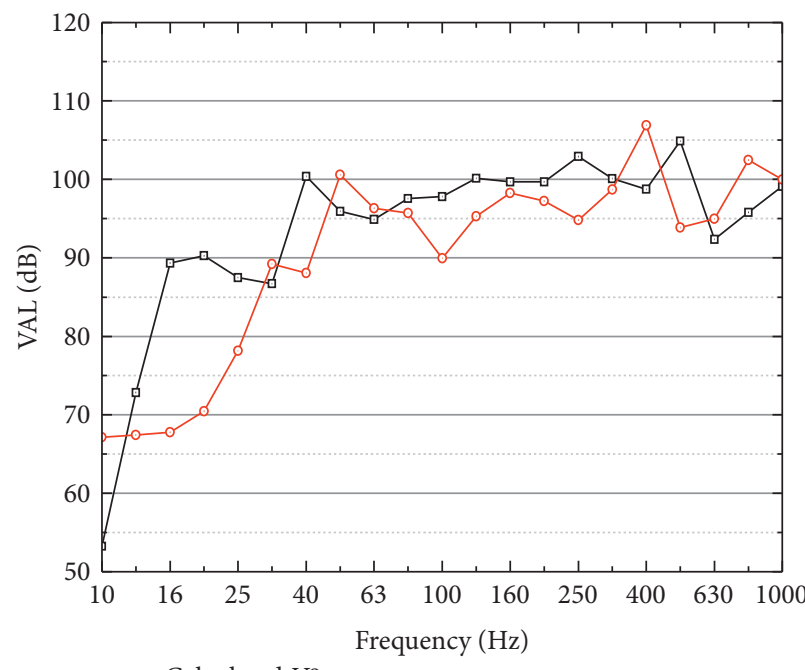

$\multimap$ Calculated $V 9$

$\rightarrow-$ Measured $V 9$

(a)

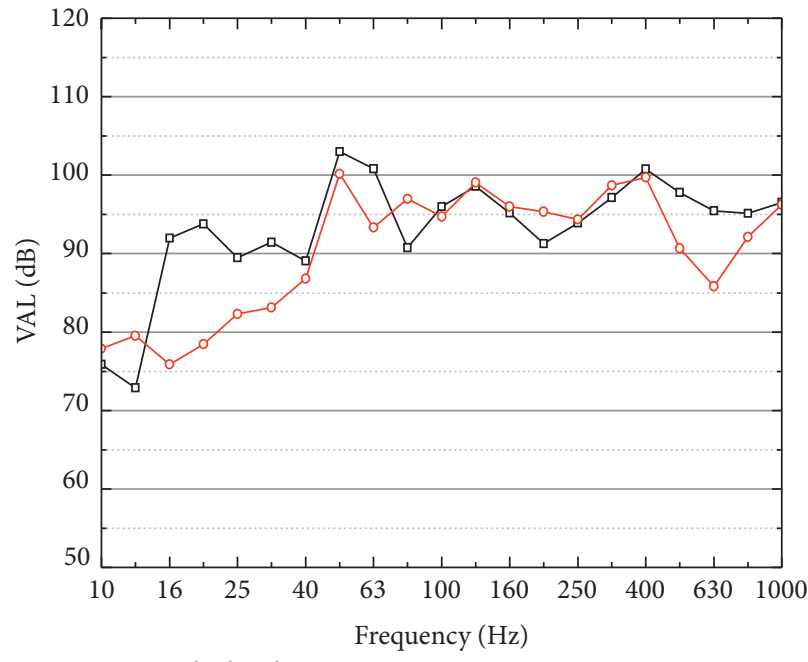

$\multimap$ Calculated V2

$\rightarrow-$ Measured V2

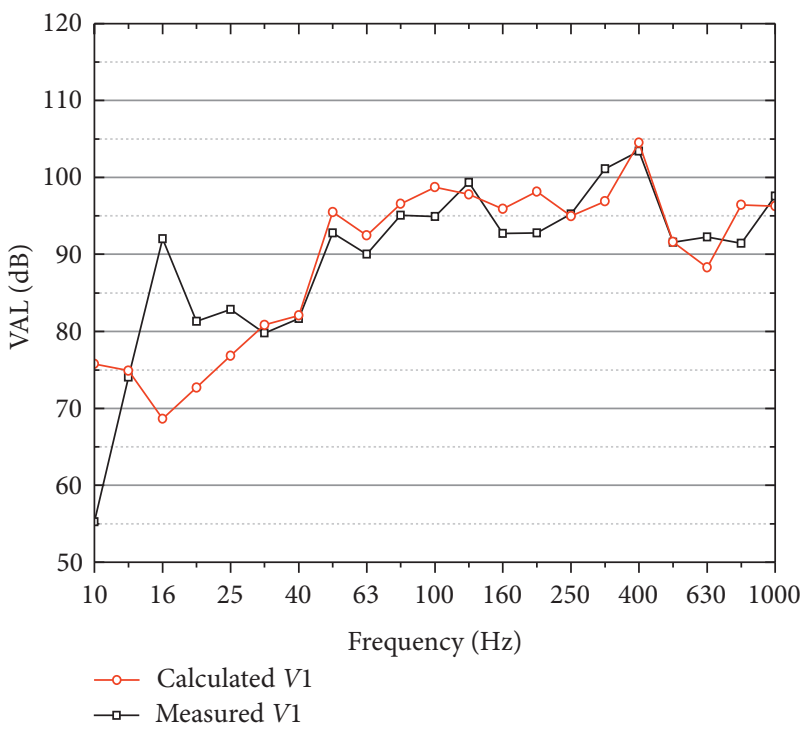

(b)

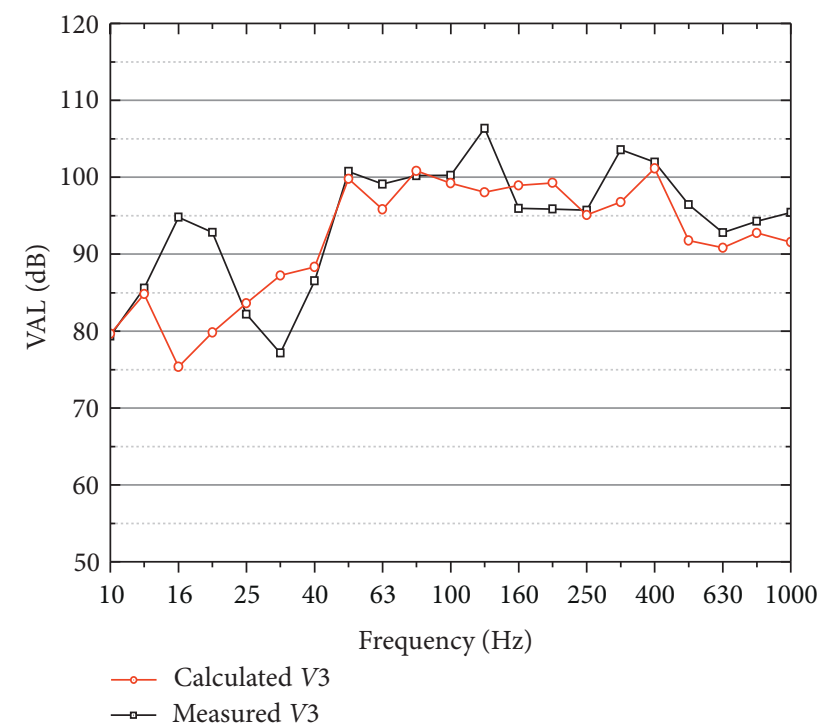

(d)

(c)

Figure 13: Comparison between test and numerical results. 
TABLE 3: Typical vibration modes of the bridge sound barrier.

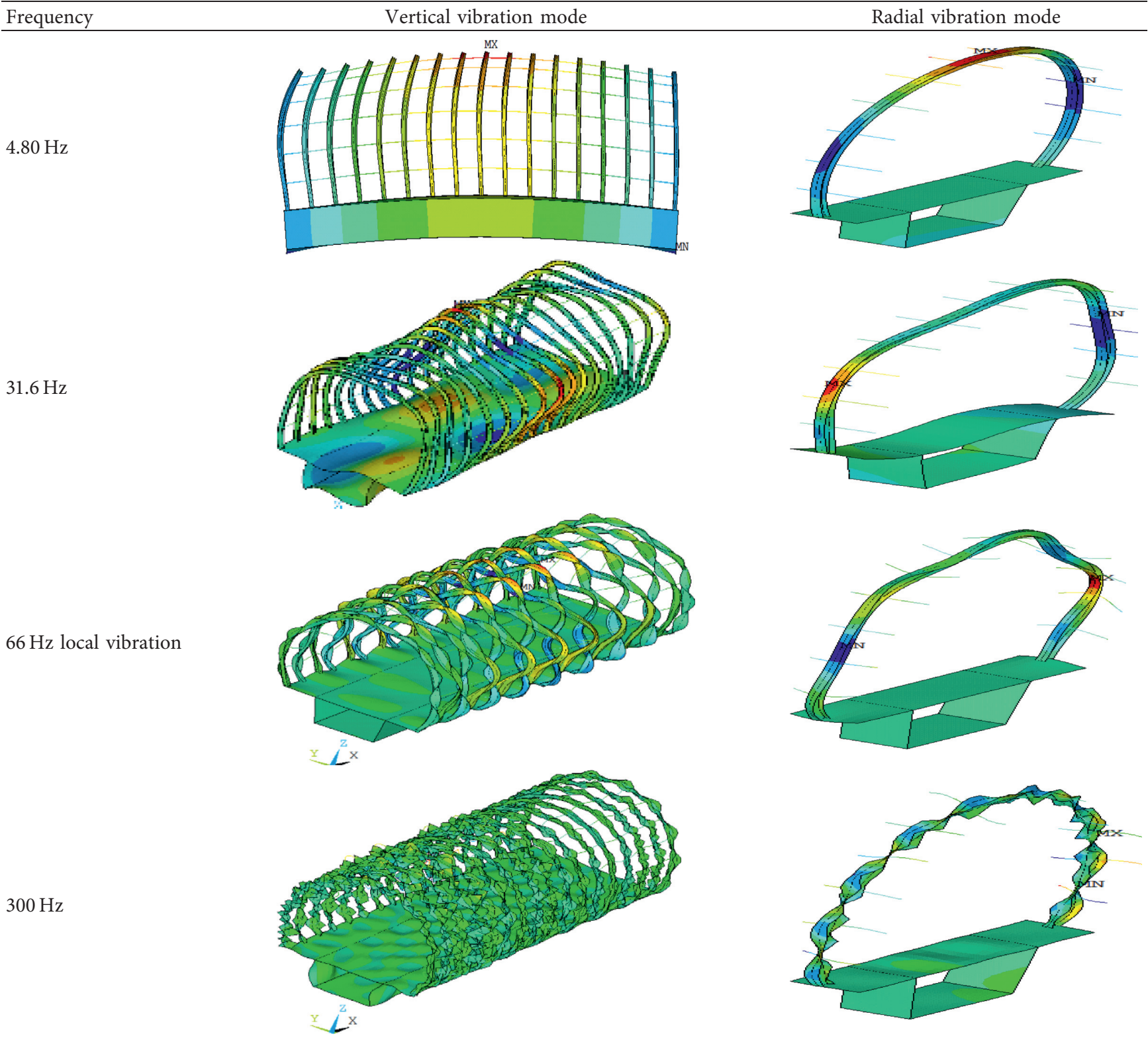

The results are similar to the downbound four points. The vibrations at the $1 / 4$ arch and $1 / 2$ arch are similar to those at symmetric upbound points near the rail with the peak VAL at 50 and $400 \mathrm{~Hz}$. The vibrations at the arch foot and $3 / 4$ arch are smaller, and their peaks VAL are at $50 \mathrm{~Hz}$ decrease at $400 \mathrm{~Hz}$. The vibration at the downbound points is $2.2 \mathrm{~dB}$ smaller than that at the upbound points.

4.3. Longitudinal Distribution. The steel arches at distances of $0,2,4$, and $10 \mathrm{~m}$ from the midspan of the bridge are selected to investigate the vibration distribution, $r$, of the steel arches along the longitudinal direction of the bridge under the movement of a train. The calculation diagram is shown in Figure 16. The calculation is also performed for the field-test case. The upbound 1/4 arch measurement point is selected for comparison. The VALs of different steel arch rings are shown in Figure 17.

As shown in Figure 17, for the arches within the range of four wheels, i.e., midspan, midspan $\pm 2 \mathrm{~m}$, and midspan $+4 \mathrm{~m}$, the spectrum laws of the VAL are essentially identical, and the peak frequency is at 50 and $400 \mathrm{~Hz}$. This is because of multiple wheels simultaneously operating on the track, which leads to interactions among nearby wheels resulting from wave propagation along the rail. However, for the arches outside the range of the wheels, i.e., midspan $\pm 10 \mathrm{~m}$, the VAL of the arch is reduced by approximately $4 \mathrm{~dB}$ at the center frequency of $400 \mathrm{~Hz}$ compared with the VALs of the arches within the range of the wheels. This is because the elastic wave decays rapidly with the increasing distance at high frequencies. 


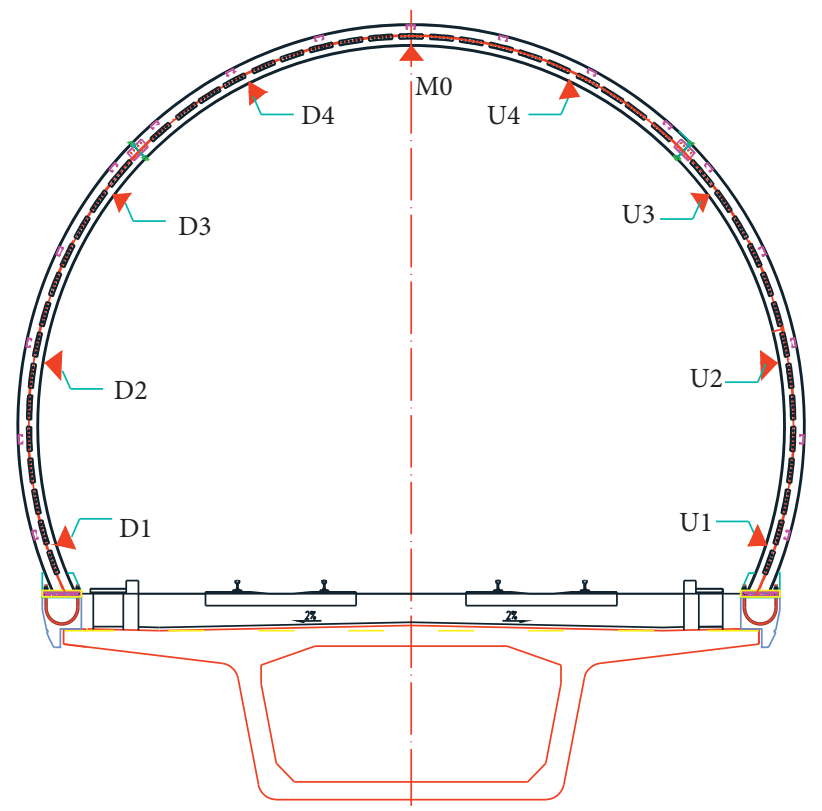

Figure 14: Layout of the measurement points.

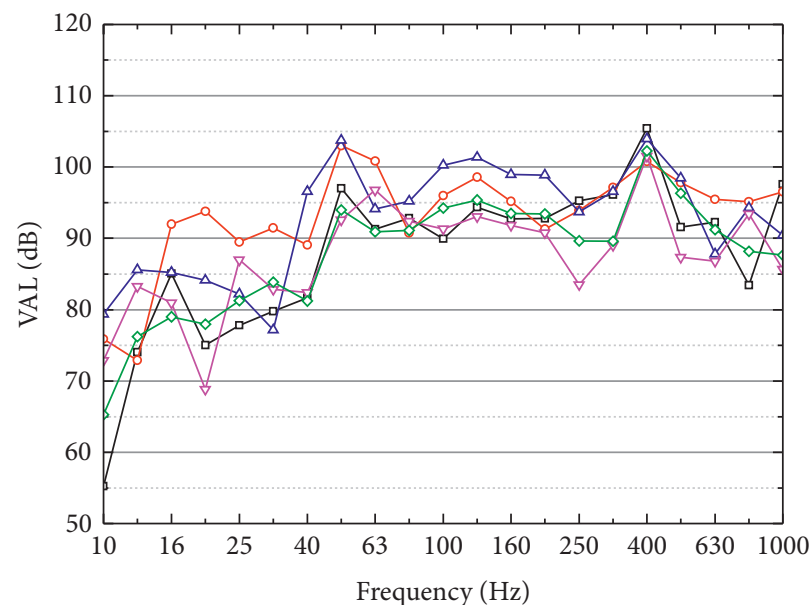

$\rightarrow$ U1

$\because$ U2

$\rightarrow$ U3

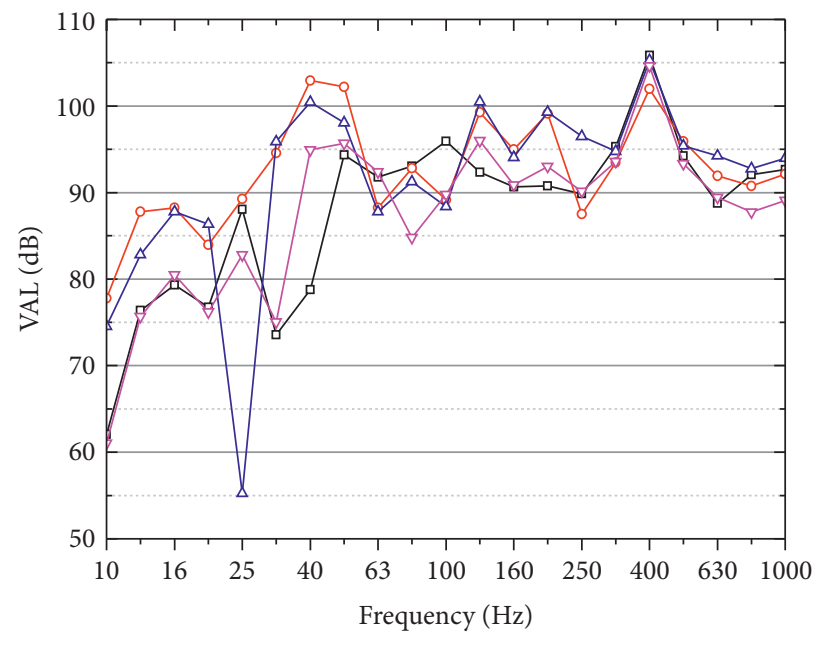

$\rightarrow \mathrm{D} 1$

$\triangle \mathrm{D} 3$

(a)

FIGURE 15: VAL distribution along the circumference of the steel arch: (a) upbound vibration; (b) downbound vibration.

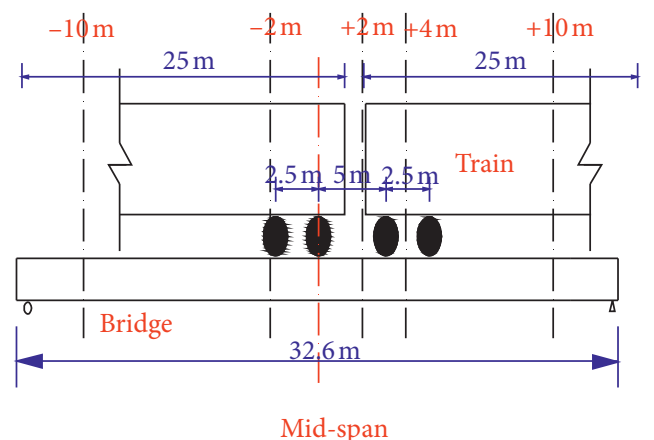

FIgURE 16: Vibration calculation diagram of different steel arches in the longitudinal direction. 


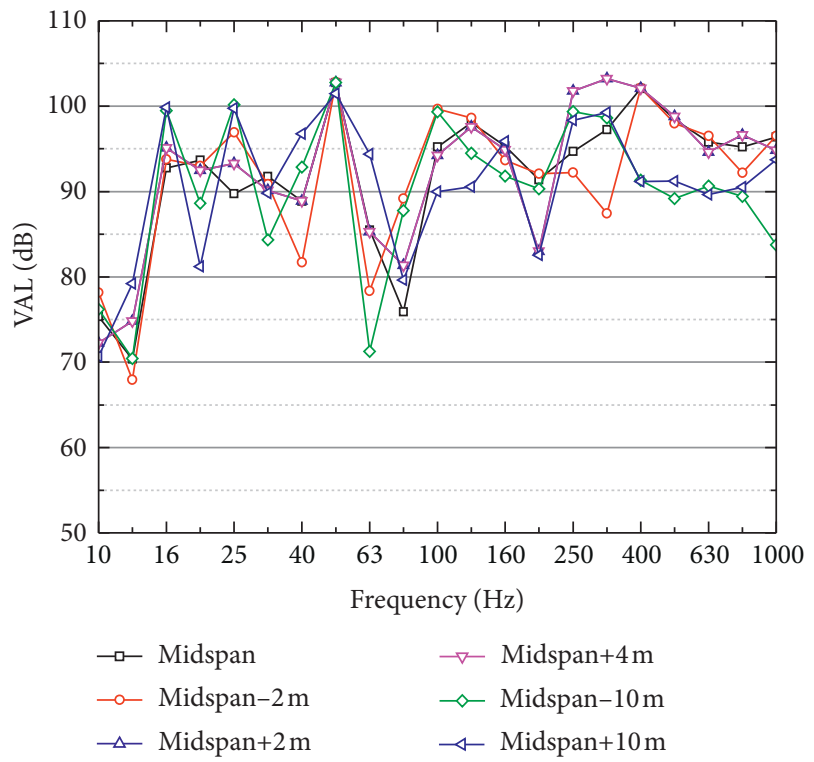

Figure 17: Longitudinal distribution of the VAL.

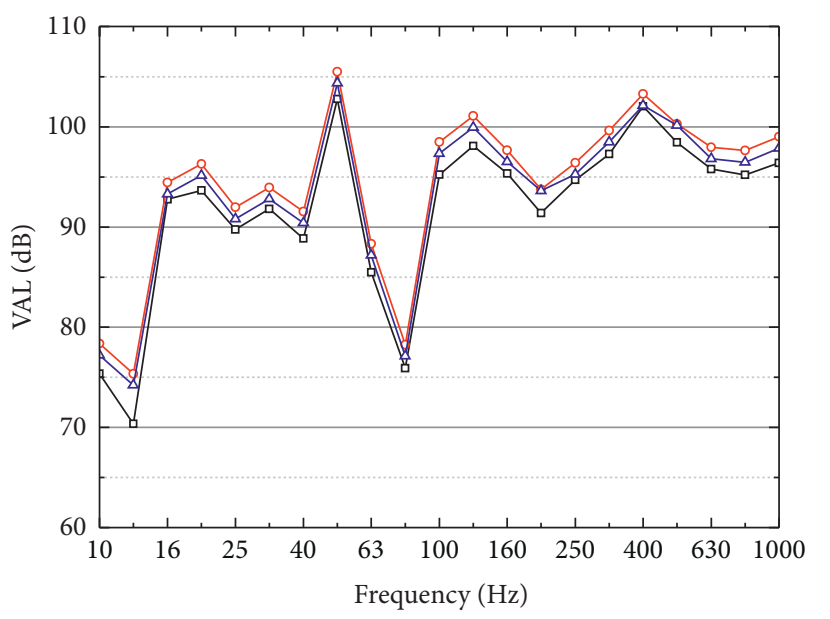

$\multimap V=110 \mathrm{~km} / \mathrm{h}$
$\multimap-V=150 \mathrm{~km} / \mathrm{h}$
$\multimap-V=130 \mathrm{~km} / \mathrm{h}$

FIGURE 18: Vibrations at different speeds.

4.4. Effect of Speed. The relationship between the vibration of the FESB and the vehicle speed is analyzed by calculating the vibration response of the FESB at speeds of 110, 130, and $150 \mathrm{~km} / \mathrm{h}$. The $1 / 4$ arch is selected as the measurement point. The VALs at the three speeds are plotted in Figure 18. As shown, at the speeds of 110,130 , and $150 \mathrm{~km} / \mathrm{h}$, the peak VALs at $50 \mathrm{~Hz}$ are $102.78,104.34$, and $105.49 \mathrm{~dB}$, respectively, and the peak VALs at $400 \mathrm{~Hz}$ are 102.05, 102.13, and $103.28 \mathrm{~dB}$, respectively. The VAL does not increase linearly with respect to the speed and compared with the VAL at the high frequency; the VAL at the low frequency increases faster with the increasing speed. This is because the vibration at the low frequency is mainly generated by the resonance of the bridge structure under the excitation of the wheel-rail interaction, which is related to the speed of the train.
However, at the high frequency, it is mainly caused by the high-order local vibration of the bridge structure, and the effect of the speed is small.

\section{Conclusion}

The vibration law of the FESB was studied through a field test and a numerical analysis. The following conclusions are drawn.

(1) According to the measured vibration of the track, bridge, and FESB, when the train passes, the steel arches of the FESB retain the frequency-spectrum characteristics of the vertical vibration of the bridge. The vibration of the FESB due to the movement of trains is mainly caused by the vertical vibration of the bridge

(2) The vibrations of steel arches are in the mid-to-low frequency range of $50-400 \mathrm{~Hz}$. With an increase in the arch height, the vibration at the high frequency of $400 \mathrm{~Hz}$ gradually decreases. The dominant frequency band of the sound insulation plates has a center frequency of $63 \mathrm{~Hz}$, and the vibrations of the plates exceed those of the arches

(3) According to the modal analysis, the vibration of the sound barrier at a low frequency is caused by the low-order local vibration of the bridge plate, and the vibration of $1 / 4-1 / 2$ arch is the largest among the measurement points used in this study

(4) When a train passes through the FESB, the vibrations at symmetric positions on the steel arch are similar. Along the longitudinal direction of the bridge, the vibrations within the action range of the multiple train wheels are similar. The vibration at a low frequency remains unchanged, and the high-frequency vibration decays rapidly $10 \mathrm{~m}$ away from the wheels. The vibration magnitude of the sound barrier increases with the train speed

\section{Data Availability}

The data used to support the findings of this study are included within the article and available from the corresponding author upon request.

\section{Conflicts of Interest}

The authors declare that they have no conflicts of interest.

\section{References}

[1] G. Sanja, J. Kristian, and D. HrVoje, "Noise barriers with varying cross-section optimized by genetic algorithms," Applied Acoustics, vol. 11, pp. 1129-1137, 2012.

[2] D. J. Oldham and C. A. Egan, "A parametric investigation of the performance of T-profiled highway noise barriers and the identification of a potential predictive approach," Applied Acoustics, vol. 72, no. 11, pp. 803-813, 2011.

[3] X. Zhang, R. Liu, Z. Cao, X. Wang, and X. Li, "Acoustic performance of a semi-closed noise barrier installed on a 
high-speed railway bridge: measurement and analysis considering actual service conditions," Measurement, vol. 138, pp. 386-399, 2019.

[4] C. Y. Zhao and P. Wang, "Minimizing noise from metro viaduct railway lines by means of elastic mats and fully closed noise barriers," Proceedings of the Institution of Mechanical Engineers, P I Mech Eng F-J Rai, vol. 232, pp. 1828-1836, 2017.

[5] X. Sheng, C. J. C. Jones, and D. J. Thompson, "A comparison of a theoretical model for quasi-statically and dynamically induced environmental vibration from trains with measurements," Journal of Sound and Vibration, vol. 267, no. 3, pp. 621-635, 2003.

[6] G. Lombaert and G. Degrande, "Ground-borne vibration due to static and dynamic axle loads of InterCity and high-speed trains," Journal of Sound and Vibration, vol. 319, no. 3-5, pp. 1036-1066, 2009.

[7] P. A. Costa, R. Calçada, and A. S. Cardoso, "Influence of train dynamic modelling strategy on the prediction of track-ground vibrations induced by railway traffic," Proceedings of the Institution of Mechanical Engineers, Part F: Journal of Rail and Rapid Transit, vol. 226, no. 4, pp. 434-450, 2012.

[8] W. Zhai, Z. Han, Z. Chen, L. Ling, and S. Zhu, "Train-track-bridge dynamic interaction: a state-of-the-art reView:A state-of-the-art review," VVehicle System Dynamics, vol. 57, no. 7, pp. 984-1027, 2019.

[9] Q. Li and D. J. Thompson, "Prediction of rail and bridge noise arising from concrete railway viaducts by using a multilayer rail fastener model and a wavenumber domain method," Proceedings of the Institution of Mechanical Engineers, Part F: Journal of Rail and Rapid Transit, vol. 232, no. 5, pp. 13261346, 2018.

[10] D. J. Thompson, Railway Noise and Vibration: Mechanisms, Modeling and Means of control, Elsevier, Oxford, UK, 2009.

[11] L. Carassale and M. Marrè Brunenghi, "Dynamic response of trackside structures due to the aerodynamic effects produced by passing trains," Journal of Wind Engineering and Industrial Aerodynamics, vol. 123, pp. 317-324, 2013.

[12] X.-Z. Li, X.-H. Liu, D.-J. Liu, and X. Zhang, "Influences of soilstructure interaction on coupled Vibration of train-bridge system: theoretical and experimental study," VAdvances in Structural Engineering, vol. 16, no. 8, pp. 1355-1364, 2013.

[13] T. X. Wu and D. J. Thompson, "Vibration analysis of railway track with multiple wheels on the rail," Journal of Sound and Vibration, vol. 239, no. 1, pp. 69-97, 2001.

[14] Q. Li, K. Wang, S. Cheng, and X. D. Song, "Vibration analysis of concrete bridges during a train pass-by using various models," Journal of Physics: Conference Series, vol. 744, Article ID 012140, 2016.

[15] N. Zhang and H. Xia, "VDynamic analysis of coupled vehiclebridge system based on inter-system iteration method," Computers and Structures, vol. 114-115, pp. 26-34, 2013.

[16] X. Li, L. Liang, and D. Wang, "Vibration and noise characteristics of an eleVated box girder paVed with different track structures," Journal of Sound and Vibration, vol. 425, pp. 21-40, 2018.

[17] L. Liang, X. Li, J. Yin, D. Wang, W. Gao, and Z. Guo, "Vibration characteristics of damping pad floating slab on the long-span steel truss cable-stayed bridge in urban rail transit," Engineering Structures, vol. 191, pp. 92-103, 2019.

[18] X. Song and Q. Li, "Numerical and experimental study on noise reduction of concrete LRT bridges," VScience of The Total Environment, vol. 643, pp. 208-224, 2018.

[19] X. Zhang, X. Li, Q. Liu, J. Wu, and Y. Li, “Theoretical and experimental investigation on bridge-borne noise under moving high-speed train," Science China Technological Sciences, vol. 56, no. 4, pp. 917-924, 2013.

[20] X. D. Song, Q. Li, and D. J. Wu, "Investigation of rail noise and bridge noise using a combined 3D dynamic model and 2.5D acoustic model," Applied Acoustics, vol. 109, pp. 5-17, 2016. 